\title{
Family Planning factors on Rural Muslim of Karnataka State
}

\author{
Bagappa Chalawadi ${ }^{1 *}$, Dr. Ashok D Holkar ${ }^{2}$
}

\section{ABSTRACT}

The fertility data indicate that there is a need to change to scenario of contraception use in India. The present paper reports the Family Planning: A Study among 100Men and 100 Women of a Rural Muslim Community in Karnataka state the information was collected through in-depth interviews with structured questionnaire. A considerable proportion of people reported that their spouse encouraged adopting family planning. And very few people reported that their spouse opposed and discouraged the use of family planning methods.

Keywords: Family Planning, Attitude, Muslim, Rural, Karnataka

Currently, India is the second most populous country in the world, contributing about $20 \%$ of births worldwide (World Health Organization, 2006). Also, it continued to have one of the most rapidly growing populations in the world. However, third National Family Health Survey (NFHS-3) reported that fertility continues to decline in India. The current total fertility rate (TFR) of 2.7 is down slightly from 2.9 children per woman at the time of second National Family Health Survey (NFHS-2), but is still well above the replacement level of just over two children per woman (International Institute for Population Sciences and ORC Macro, 2000, 2007).

India started the first national family planning programmed in the world nearly sixty years ago. Those were very different times with different realities. The life expectancy of the average Indian was more than thirty years less than it is today (thirty five years to sixty seven years),the average number of children a woman had in her lifetime was about six and about more than one fifth of infants born did not see their first birthday. Contraceptive usage had begun.

Earlier, but interestingly female sterilization, the most common contemporary contraceptive, did not exist as we know it today. Since then India's family planning programmed had a chequered history. From being a programmed which was a seen as being essentially supportive to a more

\footnotetext{
${ }^{1}$ Assistant Professor in Psychology, LBS government first grade college R T Nagar Bangalore

${ }^{2}$ Assistant Professor in Psychology, Government Arts college, Dr. B R Ambedkar veedhi Bangalore, India *Responding Author

Received: December 17, 2016; Revision Received: February 9, 2017; Accepted: February 15, 2017

(C) 2017 Chalawadi B, Holkar A; licensee IJIP. This is an Open Access Research distributed under the terms of the Creative Commons Attribution License (www.creativecommons.org/licenses/by/2.0), which permits unrestricted use, distribution, and reproduction in any Medium, provided the original work is properly cited.
} 


\section{Family Planning factors on Rural Muslim of Karnataka State}

robust maternal and child health programmed it became so big that it overwhelmed the entire health programmed in the size of its scope and budget as the fears of a 'population explosion' overwhelmed planners. From seeing development as the best contraceptive (1974), Indian policy makers moved to a radically different policy of forced sterilization within a very short time span (1975 -77). Over time men's involvement in family planning fell and it became an entirely target driven numbers game where all government officials from the subordinate village school teacher to the District Collector being judged by the number of 'tubectomies' they delivered in a year (twenty point programmed of the 1980's).

Overall contraceptive usage has increased from about $13 \%$ in the 1970 , s to $41 \%$ in $1992-93$ (NFHS1 - pre ICPD) to 56\% in 2005 -06, 2007 to 2012 (NFHS 3). For rural India this increase has been from $37 \%$ to $53 \%$. The proportionate change during this period has been more in rural India.

\section{Muslim/Non-Muslim Differentials in Fertility and Family Planning in India}

The analysis shows that socioeconomic factors do not explain lower use of family planning and higher fertility among Muslims. A reason maybe heavy reliance of India's family planning program on sterilization and Muslims 'preference for temporary methods over sterilization. Another reason may be heavy reliance of the program on public-sector sources of supply of family planning and Muslims' preference for private-sector services due to greater privacy needs. A third reason may be greater opposition to family planning among Muslims, which is indicated in surveys as their main reason for not currently using and not intending to use family planning in the future. The findings suggest that greater availability of modern temporary methods and expansion of private-sector family planning services may increase contraceptive use and lower fertility among Muslims in India.

\section{Islam and family planning}

The Quran (or Koran) is the primary source of religious authority in Islam. Hadiths (the recorded sayings of the Holy Prophet), Taqreer (verbal or silent approval of the Prophet), and Sunnah (acts of the Prophet) are other sources of religious teachings for Muslims (Khan 1979; Akbar 1974). In practice, most Muslims rely on interpretations of the Quran and other religious writings by local ulama (Islamic scholars), resulting in wide variation in the understanding of Islam across cultures and schools of religious thought (Boonstra 2001).2 Islam encourages marriage and procreation within marriage, but there is considerable uncertainty about whether Islam favors or prohibits the use of contraception (Boonstra 2001; Khan 1979; Akbar 1974). According to some, Islam is open to various interpretations regarding acceptability of contraception (Obermeyer 1994), and it neither supports nor hinders fertility decline (Karim 1997). The Quran mentions children as the "decoration of life" and forbids infanticide, which is interpreted by some to imply that Islam does not permit contraception. On the other hand, some argue that several Quranic verses imply that the "well-being of children overrides concerns for a large 


\section{Family Planning factors on Rural Muslim of Karnataka State}

family,” thereby suggesting that contraception is acceptable in Islam (Boonstra 2001; Underwood 2000). Moreover, there is evidence from some Hadiths that the withdrawal or coitus interruptus method (al'azl) was practiced by the Prophet's followers with his knowledge, and that he did not forbid it and may even have encouraged it (Boonstra 2001; Underwood 2000; Kamal n.d.; Akbar 1974). Most ulama agree that al'azl is permissible in Islam, but it should not be practiced without the woman's consent. By analogy, modern temporary methods of contraception, such as the condom and diaphragm, whichhave the same aim as the withdrawal method-to prevent the sperm from fertilizing the egg-are also generally considered permissible (Boonstra 2001; Underwood 2000; Akbar 1974). However, some ulama question the acceptability of oral contraceptives andimplants (Boonstra 2001). Most ulama agree that surgical methods to permanently endfertility, such as sterilization, are forbidden in Islam (Khan 1979; Akbar 1974). Some Islamic countries have issued fatwa (direct injunctions) that allow temporary family planning methods for medical and/or economic reasons but forbid abortion and all permanent family planning methods (Boonstra 2001; Khan 1979). There is evidence to suggest that Muslims in India prefer temporary methods of family planning over sterilization (Mistry 1999; Population Research Centre, Dharwad 1991; Caldwell and Caldwell 1988; Ranganekar et al. 1987). According to Caldwell and Caldwell (1988), the local Muslim establishment in rural south India believes that both abortion andsterilization are forbidden in Islam. Ranganekar et al. (1987) observe that Muslims in central India prefer temporary methods of contraception, while Hindus and Christians prefer permanent methods. A study conducted by the Population Research Centre, Dharwad (1991) concludes that Muslim women are more likely than Hindu women to accept IUD but not sterilization. There is evidence of Muslims' preference for nonterminal methods from other Asian countries as well (e.g., Lerman et al. 1989;

Chamratrithirong et al. 1986). Religious opposition is a frequently cited barrier to adoption of family planning among Muslims in India (Caldwell and Caldwell 1988). Several studies have noted greater opposition to family planning as a reason for lower use or lower desire for future use of contraception among Muslims than among non-Muslims (Mishra et al. 1999; Bhende et al. 1991). In other Asian countries also, Islam is believed to be a barrier to widespread acceptance of family planning, but there are exceptions. For example, in Bangladesh, Miah (1992) observes that agrarian social structure and religious beliefs are the two major forces behind high fertility in the country. Roudi (1988) also notes widespread religious objection to contraception in Bangladesh, but Bernhart and Uddin (1990) find little support for the view that there is widespread religion-based resistance to family planning among Muslims in Bangladesh. In Indonesia, the Islamic religious establishment was initially opposed to family planning, but more recently it appears to have played a critical role in making the small family norm socially acceptable (Adioetomo 1995). 


\section{Family Planning factors on Rural Muslim of Karnataka State}

\section{Objectives}

1. To study the differences in attitude towards family planning between the Men and Women of a Rural Muslim Community

\section{Hypothesis}

There would be significant differences between attitude towards family planning in Men and Women of a Rural Muslim Community.

\section{ADMINISTRATION OF THE SCALE}

The family planning and birth control attitude scale was designed and constructed with a specific purpose of assessing the opinion of the people on the much spoken crucial national problem and also a strong barrier to the development of the nation. The scale may reveal how far people are really interested in the national problem and lend their co-operation to solve the crucial problem. This scale may be used as an individual test and also as a group test. There is no time limit in answering the questionnaire. But the test user or the investigator should tell the respondents not to spend too much of times on times on each statement. But it is better that the investigator should know how much time each type of group takes to complete the questionnaire. It is expected that they should take 35 to 40 minutes to answer it. If the researcher is conducting the test on a group of people then he/she should make them to sit comfortably in a well illuminated room and there should not be any source of disturbance. The test conductor should go to the testing hall well in advance with all the test materials required and examine the hall and make proper seating arrangements for the respondents. Then he/she should give the following brief direction about filling up of the questionnaire.

"This is a questionnaire on population problems, which is consisting of 64 statements and you are required to express only your opinion on the idea given in each statement. Thereby you are helping us to assess your attitude towards the issue. This is neither an intelligence test nor a personality test. Therefore, you can freely express your opinion on the problem. You may agree with some idea and disagree with some. Whatever you feel, please express your agreement or disagreement by underlining any one of the five alternative responses given under each statement. If your agreement with the idea is strong then underline the response strongly agree, if you simply agree underline the response agree. If you were not able to decide then underline the response unable to decide. If you are not agreeing with the idea, then underline the response, disagree and if you are strongly against the idea, then underline the response, strongly disagree. There is no time limit, but try to answer as quickly as possible. As soon as you finish it you can return the booklet to me. When I say "ready go, you can start answering the questionnaire.

After giving these directions, the researcher can distribute the test booklets to the respondents and ask them to provide the personal information asked for in the front page of the booklet. They may be also asked to read the direction given at the top of the statements. When all these 


\section{Family Planning factors on Rural Muslim of Karnataka State}

formalities are over and if the respondents are ready then the researcher on verification can give the order, "Ready go". As soon as they started answering, the researcher may start the stop clock to find out how much time they are taking to complete it. One collecting the completed questionnaires from all of them the researcher may permit them to go away. It is, better to have a minimum of 40 respondents at one sitting.

In case, if the researcher is required to use the same test booklets on another group of persons, then he/she should instruct the respondents not to write anything or make any marking in the booklet and ask them to use separate scoring sheets. In this case the personal information sheet should be attached with the scoring sheet.

\section{METHOD OF SCORING}

The researcher, before starting the scoring, should check and scrutinize once whether all the items are properly answered as directed. The scoring of the responses should be made strictly according to the key, designed for the scale. Scoring the attitude scales is a procedure of converging the responses into numerical values. A quantitative treatment of the data is possible if only the responses are given numerical values. Therefore, the responses are assigned with weights ranging from 5 to 1 for the positive statements and 1 to 5 for the negative statements. Thus the strongly agree response of the positive statement is assigned with a weight of 5 , agree 4 , unable to decide 3 , disagree 2 and for strongly disagree 1 . The reverse order is given to the responses of the negative statements by assigning 1 to strongly agree, 2 to agree, 3 to unable to decide, 4 to disagree and 5 to strongly disagree response.

The total of all the weights assigned to the responses for all 64 statements constituted the individual score. The high score in the whole scale indicates favorable attitude towards family planning and birth control. In the sub-tests also the high scores indicate favorable attitude toward the respective issue. The low score indicates unfavorable attitude toward family planning and birth control and toward the respective issues. The highest possible score in the whole scale is 320 which is extremely favorable or pro attitude toward the issues and the lowest possible score is 64 which is extremely unfavorable or anti attitude toward the issues. After scoring the whole scale the scores of the eight variable may be treated separately as sub-scales for assessing the individual's or the group's score in the respective variables.

Table: Showing .Mean, SD and t-value of family planning Men and Women of a Rural Muslim in Karnataka state

\begin{tabular}{|c|c|c|}
\hline Group & \multicolumn{2}{|c|}{ Muslim } \\
\hline Mean & Rural women & Rural men \\
\hline SD & 94.02 & 106.6 \\
\hline t-valve & 9.05 & \\
\hline
\end{tabular}

Significance at* 0.01 level,

(C) The International Journal of Indian Psychology, ISSN 2348-5396 (e)| ISSN: 2349-3429 (p) | 32 
Showing graph of .Mean, SD and t-value of family planning Men and Women of a Rural Muslim in Karnataka

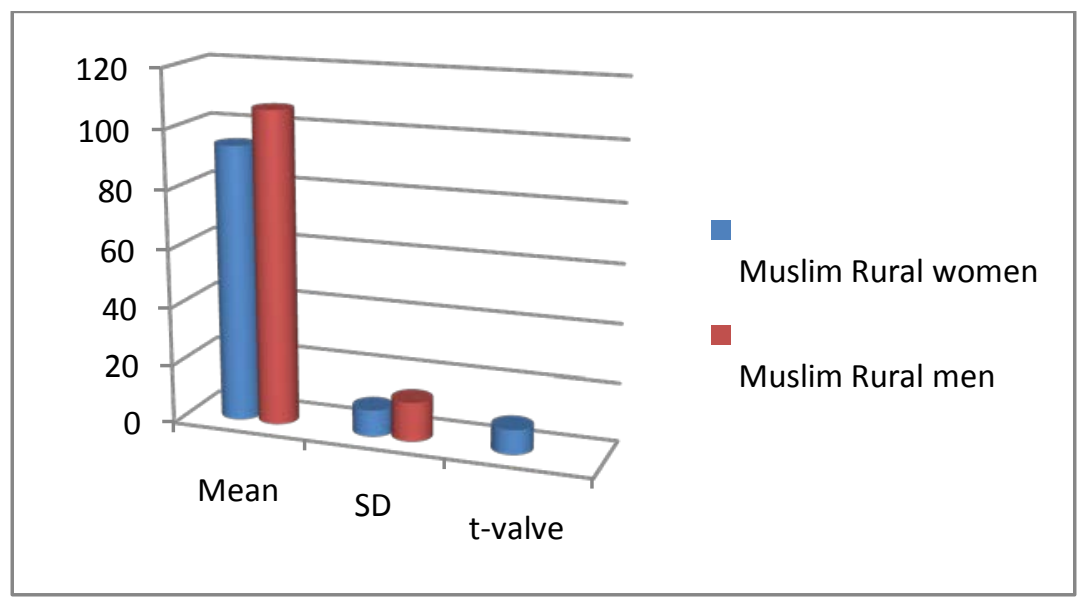

\section{RESULT AND DISCUSSION}

The mean and SD of rural women Muslim 94.04 and 106.6are lesser than Muslims men 13.41 and 9.05 respectively. The calculated' value 8.43at 0.01 level of significant. Therefore, the formulated hypothesis is that, "there would be significant differences between men rural Muslim and women rural Muslim attitude towards family planning of Karnataka state". Hence, the formulated hypothesis is accepted.

\section{CONCLUSION}

There are significant differences between Muslim rural male and Muslim rural female of family planning and birth control in attitude. More birth control attitude of rural men. Low level birth control attitude of rural female in Karnataka state. Among those who use family planning, Muslims prefer temporary methods to a greater degree than non-Muslims. The analysis indicates that Muslims' preference for temporary modern methods over sterilization is not due to their socioeconomic characteristics. This is consistent with the evidence that Muslims who use contraception are more likely to use temporary spacing methods and less likely to use sterilization (Mistry 1999; Population Research Centre, Dharwad 1991; Caldwell and Caldwell 1988; Ranganekar et al. 1987). The heavy reliance of India's family planning program on sterilization over the years, coupled with Muslims' preference for non-terminal methods, may have contributed to lower acceptance of family planning among Muslims.

\section{Acknowledgments}

The author appreciates all those who participated in the study and helped to facilitate the research process.

Conflict of Interests: The author declared no conflict of interests. 


\section{REFERENCES}

Abeykoon, A.T.P.L. 1987. Ethno-religious differentials in contraceptive accessibility and use in Sri Lanka. Population Information Centre Research Paper Series, No. 3.

Bhanot, I.V. Gandotra, M.M. and Baroda Fertility Study (1970). A Brief Report. In Asish Bose Desai, P.B. and Jain, S.P. (Complied) Studies in Demography.

Bhatia, P.S. 1990. Population growth of various communities in India-Myth and reality. Demography India, 19(1): 121-129.

Bongaarts, J. and J. Bruce. 1995. The causes of unmet need for contraception and the social content of services. Studies in Family Planning 26(2): 57-75.

Chamratrithirong, A., P. Kamnuansipla, and J. Knodel. 1986. Contraceptive practice and fertility in Thailand: Results of the third contraceptive prevalence survey. Studies in Family Planning, 17(6): 278-287.

Davis, W.L., K.W .Olson, and L. Warner. 1993. An economic analysis of teenage fertility: Some evidence from Oklahoma. American Journal of Economics and Sociology, 52(1): 85-99.

International Institute for Population Sciences and Macro International: National Family Health Survey (NFHS-3), 2005-06: India: Volume I. International Institute for Population Sciences, Mumbai (2007).

International Institute for Population Sciences and ORC Macro: National Family Health Survey (NFHS2),1998-99. International Institute for Population Sciences, Bombay (2000).

International Institute for Population Sciences: National Family Health Survey (MCH and Family Planning), India 1992-93. International Institute for Population Sciences, Bombay (1995).

Khan, M.E. 1979. Family Planning Among Muslims in India. New Delhi: Manohar Publications. Boonstra, H. 2001. Islam, women, and family planning: A primer. The Guttmacher Report on Public Policy, December 2001 Issue.

Lerman, C., J.W. Molyneaux, S. Moeljodihardjo, and S. Pandjaitan. 1989. The correlation between family planning program inputs and contraceptive use in Indonesia. Studies in Family Planning, 20(1): 26-37.

Mishra, V.K., R.D. Retherford, P.S. Nair, and G. Feeney. 1999. Reasons for Discontinuing and Not Intending to Use Contraception in India. National Family Health Survey Subject Reports, No. 13. Mumbai: International Institute for Population Sciences; and Honolulu: East-West Center.

Mistry, M. 1999. Role of religion in fertility and family planning among Muslims in India. Indian Journal of Secularism, 3(2): 1-33.

Mistry, M. 1999. Role of religion in fertility and family planning among Muslims in India. Indian Journal of Secularism, 3(2): 1-33.

Obermeyer, C.M. 1994. Religious doctrine, state ideology, and reproductive options in Islam. In Power and Decision: The Social Control of Reproduction. Eds. G. Senand R.C. Snow. Cambridge, MA: Harvard University, Center for Population and Development Studies. 


\section{Family Planning factors on Rural Muslim of Karnataka State}

Ranganekar, G., S. Sapre, and H. Singh. 1987. K.A.P. survey of contraception in Bhopal and surrounding villages. Indian Journal of Medical Sciences, 41(6):119-123.

How to cite this article: Chalawadi B, Holkar A (2017), Family Planning factors on Rural Muslim of Karnataka State, International Journal of Indian Psychology, Volume 4, Issue 2, No. 89, ISSN:2348-5396 (e), ISSN:2349-3429 (p), DIP:18.01.083/20170402, ISBN:978-1-36574162-3 